\title{
Dental Speciality Trainee National Committee Conference
}

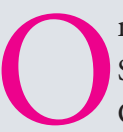
n 24 February 2017 the Dental Speciality Trainee National Committee (DSTNC) held its second conference at Birmingham Dental Hospital. The theme of the conference was 'Commissioning Specialist Dental Care in the UK', with the aim of covering a topic that was relevant for all dental specialty registrars (StRs).

The DSTNC was set up in 2013 by a group of forward thinking StRs with the aims of providing a voice and representation for all dental StRs, supporting trainees, providing better communication networks between specialities and advising national groups, committees and relevant bodies. The group consists of representatives from each of the dental specialties, a Joint Committee for Postgraduate Training in Dentistry Specialty Trainee representative, and other invited guests. The first DSTNC conference was held in Manchester in 2015 with a theme around leadership and management.

This free biennial conference attracted over 80 specialty trainees from all 13 specialties nationwide. The delegates were welcomed by Joanna May, DSTNC chair.
The morning session was opened by Dr Janet Clarke MBE, Deputy Chief Dental Officer for England, with her perspective on the future of commissioning specialist dental services in England. She commented how important a topic dental commissioning was for all dental StRs and congratulated the DSTNC on their foresight to have organised the conference around commissioning. This was followed by a joint presentation from Nuala Woodman, Deputy Head of Dental Commissioning, NHS West Midlands, and Dr Mary Tomson, Consultant in Dental Public Health, on how dental services are commissioned. Dr Margie Taylor, Chief Dental Officer for Scotland then provided her standpoint on the future of commissioning specialist dental services in Scotland. The morning session was closed by Mr Patrick Kavanagh, GDC Policy Manager, discussing the role of the GDC on quality assuring dental specialty training and dentists providing tier 2 services.

The afternoon session began with a talk by Dr Joanna Johnson, Non-Restorative Service Lead, Dental Directorate Guy's, King's and St Thomas' NHS Foundation Trust, that gave insight into the commissioning of specialist dental services in secondary care. Following this, Mr Nick Ransford, Consultant in Special Care Dentistry (SCD) and Chair of the Managed Clinical Network (MCN) in SCD, Birmingham and the Black Country explained the role of MCNs and lessons learned from SCD. The conference was closed with an entertaining and informative presentation from Dr Samit Shah, NHS England, who shared his experience of business case development in a dental context.

The speakers welcomed the insightful questions, thoughts and opinions of the StR delegates throughout the conference. Verbal feedback on the day from the StRs was hugely positive, with both speakers and delegates commenting that they would like the conference to be held annually. The DSTNC thank 3M, The Royal College of Physicians and Surgeons of Glasgow, TOC Orthodontic and Specialist Dental Supplies and GlaxoSmithKline for their sponsorship. Special thanks to the University of Birmingham for the use of their state of the art facilities.

By Claire Harwood, StR Oral Surgery,

Charles Clifford Dental Hospital, Sheffield and DSTNC Secretary

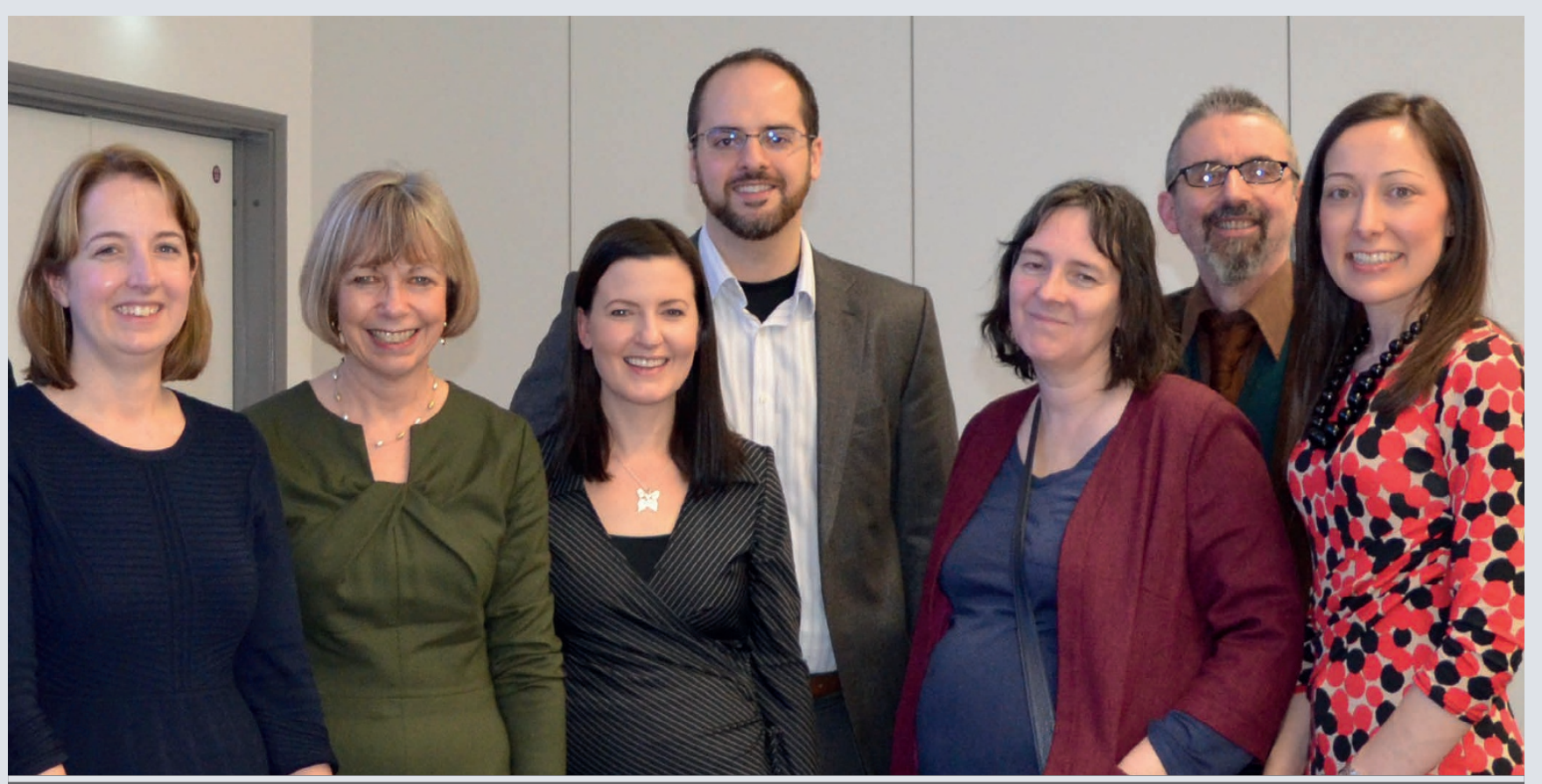

From L to R: Joanna May, Dr Janet Clarke MBE (speaker), Claire Harwood, Zaid Ali, Dr Mary Tomson (speaker), Mr Patrick Kavanagh (speaker), Nuala Woodman (speaker) 